\title{
Multidisciplinary treatment strategy for early rectal cancer
}

\section{A review}

\section{Gyung Mo Son ${ }^{1}$, In Young Lee ${ }^{1}$, Sung Hwan $\mathrm{Cho}^{1}$, Byung-Soo Park ${ }^{1}$, Hyun Sung Kim ${ }^{1}$, Su Bum Park ${ }^{2}$, Hyung Wook Kim², Sang Bo Oh ${ }^{3}$, Tae Un Kim ${ }^{4}$, Dong Hoon Shin ${ }^{5}$}

\author{
${ }^{1}$ Department of Surgery, Pusan National University Yangsan Hospital, Yangsan, Korea \\ ${ }^{2}$ Department of Internal Medicine, Pusan National University Yangsan Hospital, Yangsan, Korea \\ ${ }^{3}$ Department of Hemato-oncology, Pusan National University Yangsan Hospital, Yangsan, Korea \\ ${ }^{4}$ Department of Radiology, Pusan National University Yangsan Hospital, Yangsan, Korea \\ ${ }^{5}$ Department of Pathology, Pusan National University Yangsan Hospital, Yangsan, Korea
}

Received: October 21, 2021

Revised: November 17, 2021

Accepted: December 6, 2021

Corresponding author:

Gyung Mo Son

Department of Surgery, Medical

Research Institute, Pusan

National University School of

Medicine and Research Institute

for Convergence of Biomedical

Science and Technology,

Pusan National University

Yangsan Hospital, 20 Geumo-ro,

Mulgeum-eup, Yangsan 50612,

Korea

Tel: +82-55-360-2124

E-mail:skm1711@pusan.ac.kr

\begin{abstract}
The early rectal cancer (ERC) has increased with the national cancer screening project for early detection of colorectal cancer. The gold standard treatment for low rectal cancer is low anterior resection (LAR) based on total mesorectal excision. However, radical resection results in a high mortality and complication rate, and the deterioration of quality of life due to LAR syndrome, genitourinary dysfunction, and possible permanent stoma. Local excision with chemoradiation therapy could be one of the alternative therapeutic strategies for the organ preservation and a cure of cancer. To decide the treatment strategies, it is important to establish sophisticated indications that can maximize the therapeutic effect. ERC has heterogeneous pathological features, including aggressive behavior and occult lymph node metastasis, with different responses to chemoradiotherapy. Therefore, radiologic, endoscopic and pathologic evaluation to predict the risk of lymph node metastasis and local recurrence has been evolving to determine the optimal treatment strategy in the patient-tailored medicine. Recently, the long-term outcomes of prospective randomized clinical trials provide new hope for organ preservation in patients with ERC. In this paper, we aim to review various risk factors related to local recurrence and discuss the optimal treatment strategy for ERC.
\end{abstract}

Keywords: Colonoscopy; Neoadjuvant therapy; Organ preservation; Rectal neoplasms; Transanal endoscopic surgery

\section{INTRODUCTION}

Colorectal cancer is one of the most common gastrointestinal cancers in Korea [1]. Rectal cancer has the highest frequency, accounting for almost half of colorectal cancers. Oncologic out- 
comes have improved remarkably over recent decades with the development of multidisciplinary treatment for rectal cancer. Neoadjuvant chemoradiation therapy (CRT), radical resection based on total mesorectal excision (TME), and adjuvant chemotherapy have improved the survival and recurrence rates of locally advanced rectal cancer $[2,3]$.

Recently, the diagnosis rate of early rectal cancer (ERC) has increased during the ongoing national gastrointestinal cancer screening project for early detection of colorectal cancer. Moreover, life expectancy and the number of elderly patients are increasing, and this population has a high risk of surgical complications and mortality due to various comorbidities [4, 5].

The gold standard sphincter preserving surgical treatment for low rectal cancer is low anterior resection (LAR) based on TME. However, a mortality rate of $1 \%$ to $4 \%$, a high complication rate of $40 \%$, and the deterioration of quality of life (QOL) due to LAR syndrome, genitourinary dysfunction, and possible permanent stoma are consequences of radical resection associated with increased mortality [6-8]. The desire for organ preservation and a cure of cancer has led to an increased interest in local excision and CRT as alternative therapeutic strategies for radical surgery $[9,10]$. In order to apply these treatment strategies in a patient-specific manner, it is important to establish sophisticated indications that can maximize the therapeutic effect. ERC has heterogeneous pathological features, including aggressive behavior and occult lymph node metastasis, with different responses to CRT [11]. Therefore, predicting the risk of lymph node metastasis and local recurrence based on the pathological characteristics of ERC is important to determine the optimal treatment strategy for each patient. By establishing a specific treatment strategy for ERC, it may be possible to obtain favorable oncologic results, as well as satisfactory maintenance of both the patient's physical function and QOL [12].

Recently, rapid medical progress has been made in various fields, such as minimally invasive surgery and robotic surgery, remarkable advances in endoscopic imaging diagnosis and resection techniques, and radiology evaluation using high-resolution magnetic resonance imaging (MRI) and endorectal ultrasonography. These advances have led to the development of treatment strategies for ERC [13]. Indeed, recent several reports on the long-term outcome of a multicenter prospective randomized clinical trial (RCT) using a conservative treatment strategy provides new hope for organ preservation in patients with ERC [14].

In this paper, we aim to evaluate various risk factors related to local recurrence based on a literature review and discuss the optimal multidisciplinary treatment strategy for ERC.

\section{DEFINITION OF ERC}

Initially, it is important to establish the definition of ERC. In general, stage I (T1-2NOM0) is considered an early cancer. Recently, the European Association for Endoscopic Surgery (EAES) provided a more comprehensive and practical definition of ERC: "a rectal cancer with good prognostic features that might be safely removed, preserving the rectum and that will have a very limited risk of relapse after local excision" [15]. This definition indicates that the field of ERC is expanding to include patients in which organ preservation treatment strategies can be successfully applied. In other words, the definition is intended to cover all types of rectal cancer of various stages that can be cured via organ preservation strategies, including surgical treatment, chemotherapy, and radiotherapy. Indeed, the definition of ERC has been expanded to include a heterogeneous patient group with ERC, thereby aiding clinicians in deciding the appropriate treatment strategies for this group of patients. Therefore, this comprehensive definition of ERC can be used when selecting patients for various ongoing RCTs [16-18]. In this review, ERC was limited to stage I (T1-2NOM0). However, some reference studies included a small T3 with a low-risk group.

Various treatments can be applied for rectal cancer, which depend on the distance of the tumor from the anal border. In general, low rectal cancer includes rectal cancer within 8 to $10 \mathrm{~cm}$ of the anal verge or rectal cancer below the peritoneal reflection level [19]. Lower rectal cancer may require sphincter-saving surgery, abdominoperineal resection (APR), and permanent colostomy depending on anal sphincter invasion. Low rectal cancer can easily metastasize to the lateral pelvic node and may require radiation therapy. Radical resection can lead to functional deterioration of the pelvic organs especially located below pelvic floor muscle which requiring intersphincteric resection for sphincter preservation. Low rectal cancer may also involve an area where local excision has been applied, since it is easily accessible through the anus. Therefore, the debate regarding organ preservation as a treatment strategy for lower rectal cancer is an important landmark in this field [20]. Conversely, for upper rectal cancer, the cancer biology is similar to that of sigmoid colon cancer, and if there is no invasion of the surrounding organs, radiation therapy can be omitted, and adjuvant chemotherapy can be administered with the same treatment strategy as 
that for sigmoid colon cancer [21]. Radical resection is possible with tumor-specific mesorectal excision with a $5 \mathrm{~cm}$ distal margin. Therefore, the risk of pelvic organ dysfunction after tumor-specific mesorectal excision is much lower than that after TME [22]. Since the possibility of anastomotic leakage and permanent stoma is low, surgeons can safely perform radical resection for upper rectal cancer. Therefore, in this review, various treatment strategies will be discussed for ERC in the lower rectum located within 8 to $10 \mathrm{~cm}$ of the anal verge.

\section{SURGICAL TREATMENT FOR ERC}

\section{Issues with traditional radical resection}

The main surgical treatment for low rectal cancer is TME. LAR, intersphincteric resection, and APR, including TME and regional lymphadenectomy, are associated with surgery-related mortality, risk of serious postoperative complications, and decreased QOL. LAR syndrome, including symptoms such as urgency, frequency, fragmentation, and tenesmus, occurs due to loss of rectal reservoir function and disorganized bowel movement [2]. In the case of APR, colostomy must be maintained for the duration of the patient's life. Therefore, the aim of oncological cure of radical resection should be substituted for patient QOL. Therefore, there is a growing interest in alternative treatments that can avoid stoma and surgical complications such as anastomotic leakage or LAR syndrome while preserving anorectal and urogenital function [23].

\section{Advancement of the local excision}

Local excision for ERC is an alternative to radical resection. Local excision includes endoscopic tumor resection, conventional transanal tumor excision (TAE), transanal endoscopic microsurgery (TEM), and transanal minimally invasive surgery (TAMIS) using a specialized transanal surgical platform [24]. Conventional TAE has been widely practiced for treating low rectal cancer within $8 \mathrm{~cm}$ of the anus, since it is easily accessible through the anus. However, en bloc resection can be difficult in TAE due to a narrow field of view and insufficient manipulation space; additionally, the risk of tumor fragmentation and surgical margin involvement increases. Incomplete resection can interrupt pathologic evaluation and lead to an increased local recurrence rate and decreased survival rate, including those associated with ERC.

Efforts to overcome the limitations of incomplete resection by TAE have led to the development of a transanal surgical platform. TEM, first reported by Bruess in 1984, enabled intraluminal tumor resection up to $20 \mathrm{~cm}$ above the anus with a specially designed scope and surgical instrument, namely a rectoscope with a diameter of $4 \mathrm{~cm}$. However, the abrupt learning curve and expensive surgical equipment hindered transmission of TEM [25]. In order to compensate for these shortcomings of TEM, a lightweight platform was developed as TAMIS which can be used in combination with a laparoscopic surgical system. TAMIS has the advantages of low cost and easy learning curve [26].

Compared with conventional TAE, TEM, and TAMIS showed a lower local recurrence rate. This is due to the fact that en bloc resection was easily performed using a dedicated surgical instrument suitable for minimally invasive surgery with improved visualization. TEM and TAMIS showed similar oncological results [27]. Therefore, both TEM and TAMIS are currently accepted as transanal surgical platforms that can facilitate precise local excision. Recently, a single-port robotic surgical system can provide a sophisticated 3-dimentional view and a more ergonomic approach to transanal surgery [28-30].

\section{The overlooked threat of the local excision}

The development of a transanal surgical platform and the patient's desire for organ preservation accelerated the spread of local excision in ERC, even in the absence of level I evidence [31,32]. In the United States, since the 1980s, local excision has been the surgical treatment used in almost half of the patient population with ERC. However, after a few years, the local recurrence rate increased rapidly to $20 \%$ to $40 \%$. This was an unacceptably high level compared to the rate of $1 \%$ to $4 \%$ for radical resection. Therefore, these initially overlooked disadvantages resulted in increased awareness in the field of ERC surgical treatment. Concerns associated with local excision were well-documented in the U.S. National Cancer Database including ERC patients diagnosed between 1994 and 1996 [33]. This was confirmed by the UK TEM collaboration group, as the local recurrence for a 10year period was significantly higher in patients with TEM than in the radical resection group [34]. The cause of increased local recurrence associated with local excision in ERC was immediately investigated. Analysis of various clinical and pathological factors associated with local recurrence revealed undetected occult lymph node metastasis, incomplete tumor resection, and aggressive biological features of ERC $[35,36]$. 


\section{RISK FACTORS ASSOCIATED WITH LOCAL RECURRENCE IN ERC}

The most important determinant of prognosis in ERC is lymph node metastasis. Local excision inherently excludes lymphadenectomy, thereby allowing regional lymph nodes to remain and rectal cancer cells to spread. Therefore, risk factors for predicting lymph node metastasis are very important when determining the treatment strategy of local excision and radical resection for ERC [37]. Pathological risk factors include the histologic grade of cancer cell differentiation, invasion depth, lymphovascular invasion, perineural invasion, deep submucosal (SM) invasion (>1,000 $\mu \mathrm{m}$ ), and tumor budding. The resection margin involved after local excision is the most dangerous risk factor [38]. Radical resection is required if these risk factors are present [39]. However, these pathologic risk factors for the aggressive behavior of ERC can only be identified through the pathologic examination of resected specimens. In order to accurately evaluate the pathological risk factors to determine the appropriate treatment strategy, the decision to perform a local excision has to be made. This decision can be aided in part by advanced endoscopic evaluation and resection for malignant rectal polyps.

\section{Pelvic MRI for detection of lymph node metastasis}

Preoperative pelvic MRI is essential for the detection of lymph node metastasis. MRI morphological features of lymph nodes, such as margin irregularity, heterogeneity of nodal texture, and shape, are useful for distinguishing benign and malignant tumors. Lymph nodes with uniform, homogenous signal intensity is less likely to be metastatic; meanwhile, lymph nodes with irregular borders or mixed signal intensity are judged as metastatic lymph nodes [40,41].

Although lymph node metastasis is evaluated using various features, such as lymph node size, round shape, and spiculated surface, the diagnostic accuracy of lymph node metastasis is still only about $70 \%$. Based on meta-analyses [42-44], MRI diagnostic sensitivity of metastatic lymph nodes in rectal cancer is $66 \%$ to $77 \%$ and specificity is $71 \%$ to $76 \%$. Interestingly, a significant portion of metastatic lymph nodes are less than $3 \mathrm{~mm}$ in size, which impairs the diagnostic accuracy of occult lymph node metastasis on preoperative MRI. In fact, $15 \%$ to $17 \%$ of lymph nodes smaller than $5 \mathrm{~mm}$ in rectal cancer are reported as metastatic lymph nodes. Since metastatic lymph nodes are distributed over a very wide range of lymph node sizes, small metastatic lymph nodes may be understaged, while large reactive lymph nodes may be overstaged [40,45]. Therefore, even if local excision is performed after evaluating for lymph node metastasis by a pelvic MRI before surgery, the possibility of occult lymph node metastasis remains.

\section{Endoscopic optical evaluation for invasion depth}

When a malignant rectal polyp is observed on colonoscopy, the size of the polyp and the gross morphology based on the Paris classification must be identified [46]. Pedunculated malignant polyps can be safely removed using snare polypectomy. For non-pedunculated polyps, an appropriate method for endoscopic resection can be selected based on the tumor size. Polyps within $2 \mathrm{~cm}$ size can be safely resected through endoscopic mucosal resection and those larger than $2 \mathrm{~cm}$, through endoscopic SM dissection [47]. Non-pedunculated polyps with depression (type Ilc) are associated with an increased likelihood of SM invasion. Therefore, in non-pedunculated polyps with depression or non-lifting sign, additional optical evaluation using magnifying endoscopy and magnifying chromoendoscopy (MCE) can be performed [48].

Recent breakthroughs in optical equipment have surprisingly progressed the field of endoscopic diagnosis. The narrow band image (NBI) selectively controls the wavelength of light and allows a detailed examination of the mucosal surface using shallow light transmittance. An NBI using magnifying endoscopy enables the exploration of the capillary pattern of the mucosal surface. An NBI can predict the risk of invasive rectal cancer by evaluating mucosal color, surface morphology, and capillary pattern [49]. The endoscopy experts group, formed by Japan, the United States, and Europe, developed the Narrow Band Imaging International Colorectal Endoscopic (NICE) classification for the endoscopic diagnosis of ERC. The NICE classification was able to differentiate benign adenoma, intramucosal carcinoma, superficial SM carcinoma, and deep SM carcinoma based on microscopic changes in the mucosa that can be observed with an endoscope (Table 1) [50]. The classification of capillary patterns using magnifying endoscopy can be performed more precisely. Various evaluation tools, such as Sano, Hiroshima, Showa, and Jikei classification have been developed in Japan; the Japan NBI Expert Team (JNET) classification was proposed as an integrated classification system in a consensus meeting, and its usefulness has been proven through validation studies (Table 2) [50].

The Dutch T1 colorectal cancer working group performed the multicentre prospective evaluation of real-time optical diagnosis of $\mathrm{T} 1$ colorectal cancer in large nonpedunculated 
PRECISION AND FUTURE MEDICINE

Treatment strategy for early rectal cancer

Table 1. Narrow Band Imaging International Colorectal Endoscopic (NICE) classification for the endoscopic diagnosis of early rectal cancer [50]

\begin{tabular}{|c|c|c|c|}
\hline & Type 1 & Type 2 & Type 3 \\
\hline Color & Same or lighter than background & $\begin{array}{l}\text { Browner relative to background (verify } \\
\text { color arises from vessels) }\end{array}$ & $\begin{array}{l}\text { Brown to dark brown relative to } \\
\text { background; sometimes patchy } \\
\text { whiter areas }\end{array}$ \\
\hline Vessles & $\begin{array}{l}\text { None, or isolated lacy vessels may be } \\
\text { present coursing across the lesion }\end{array}$ & $\begin{array}{l}\text { Brown vessels surrounding white } \\
\text { structures }\end{array}$ & $\begin{array}{l}\text { Has area of disrupted or missing } \\
\text { vessels }\end{array}$ \\
\hline Surface pattern & $\begin{array}{l}\text { Dark or white spots of uniform size, or } \\
\text { homogeneous absence of pattern }\end{array}$ & $\begin{array}{l}\text { Oval, tubular or branched white } \\
\text { structures surrounded by brown vessels }\end{array}$ & $\begin{array}{l}\text { Amorphous or absent surface } \\
\text { pattern }\end{array}$ \\
\hline Most likely pathology & Hyperplastic \& sessile serrated polyp & Adenoma & Deep submucosal invasive cancer \\
\hline
\end{tabular}

Adapted from Wang et al. [50].

Table 2. The Japan NBI Expert Team (JNET) classification [50]

\begin{tabular}{|c|c|c|c|c|}
\hline & Type 1 & Type 2A & Type 2B & Type 3 \\
\hline Vessel pattern & Invisible & $\begin{array}{l}\text { Regular caliber } \\
\text { Regular distribution } \\
\text { (meshed/spiral pattern) }\end{array}$ & $\begin{array}{l}\text { Variable caliber } \\
\text { Irregular distribution }\end{array}$ & $\begin{array}{l}\text { Loose vessel areas } \\
\text { Interruption of thick vessels }\end{array}$ \\
\hline Surface pattern & $\begin{array}{l}\text { Regular dark of white spots } \\
\text { Similar to surroungding } \\
\text { normal mucosa }\end{array}$ & $\begin{array}{l}\text { Regular (tubular/ } \\
\text { branched, papillary) }\end{array}$ & Irregular of obscure & Amorphous areas \\
\hline Most likely histology & $\begin{array}{l}\text { Hyperplastic polyp/sessile } \\
\text { serrated polyp }\end{array}$ & $\begin{array}{l}\text { Low grade intramucosal } \\
\text { neoplasia }\end{array}$ & $\begin{array}{l}\text { High grade intramucosal } \\
\text { neoplasia/shallow } \\
\text { submucosal invasive cancer }\end{array}$ & $\begin{array}{l}\text { Deep submucosal invasive } \\
\text { cancer }\end{array}$ \\
\hline
\end{tabular}

Adapted from Wang et al. [50].

$\mathrm{NBI}$, the narrow band imaging.

colorectal polyps using narrow band imaging (the OPTICAL study). Sensitivity of optimal diagnosis is still limited as $63.3 \%$, but specificity of predicting endoscopically unresectable lesion with deep SM invasion was accurate as 99.0\% [51]. The EndoCAR group in the Spain also validated NICE classification to identify deep SM invasion in colorectal malignant polyp [52]. So, the use of advanced endoscopic imaging techniques including NBI and chromoendoscopy could increase the accuracy of differentiation between shallow or deep SM invasion of ERC and reduce unnecessary surgical referral for lesions amendable to endoscopic resection [53]. Conversely, it can reduce unnecessary preoperative endoscopic resection for lesions that require immediate surgical resection and help patients in economic terms.

Using MCE, the Kudo's pit pattern can also be used to predict deep SM carcinoma. After applying crystal violet, the mucosa was observed using chromoendoscopy to evaluate the shape of the mucosal gland orifice [54]. If the shape is irregular (Type Vi) or non-organized (Type $\mathrm{Vn}$ ), the probability of deep SM carcinoma is $6 \%$ and $54 \%$, respectively [55]. In cases where deep SM invasion is suspected using polyp morphology, size, capillary pattern, and pit pattern, endoscopic ultrasonography may be used to assess the depth of invasion. If endoscopic advanced imaging evaluation is applied step by step, optical diagnosis of deep SM invasion could be improved [56].

In general, the degree of SM invasion was evaluated by dividing the submucosa into thirds using the Kikuchi classification [57]. When the submucosa is divided into thirds, it is divided into superficial, middle, and deep layers, and the deepest layer is called SM3. If the entire thickness of SM layer cannot be excised by endoscopic SM resection, it is inaccurate to divide SM layer into thirds, so SM1 cannot be used for risk assessment. Therefore, invasive depth less than 1,000 $\mu \mathrm{m}$ is used as alternative for SM1.

Superficial SM1 lacks lymphatic channels; therefore, there is little chance of lymph node metastasis. Thus, endoscopic resection can be performed safely to the superficial SM (SM1) adenocarcinoma. However, deep SM or SM3 invasion increases the risk of lymphovascular invasion, and the probability that it 
is accompanied by lymph node metastasis is quite high [58]. Therefore, if SM3 invasion is suspected, only targeted biopsy should be performed, and surgical resection should be considered.

If deep SM invasion is suspected and endoscopic resection is excessively performed, involvement of the resection margin and the risk of remnant tumor increases [59]. Therefore, it is desirable to apply endoscopic resection selectively in intramucosal carcinoma or superficial SM carcinoma, where endoscopic resection can effectively secure a safe resection margin [60].

However, even with safe endoscopic resection, there are many cases in which pathologic high risk is confirmed. In a previous study, when patients with ERC with pathologic high risk were compared with primary TME and completion TME after endoscopic resection, there was no oncological difference [61]. Therefore, endoscopic tumor evaluation and endoscopic resection by an experienced endoscopist can be safely performed for accurate pathological diagnosis and, sometimes, can serve as a tool for local excision in patients with ERC [62].

\section{Pathologic evaluation of risk factors}

If the resected tissue has a clear resection margin and satisfies all favorable factors, such as well- or moderate differenti- ation, SM1 invasion $(<1,000 \mu \mathrm{m})$, negative lymphovascular invasion, and tumor budding (G1), local excision can be considered a safe oncologic treatment (Fig. 1) [19]. In Japan and Korea, SM invasion $(>1,000 \mu \mathrm{m})$ is used as a risk factor, but only SM3 or deep SM invasion is used as a definite worse prognostic factor in Western textbooks. So, SM invasion (>1,000 $\mu \mathrm{m})$, or SM3 invasion should be considered as risk factor requiring surgical resection. Kikuchi's SM classification can be evaluated in pathological tissues obtained by full thickness resection. However, in endoscopic resection, it is difficult to distinguish SM3 since the muscularis propria layer is not included. In a study comparing the vertical invasion distance of cancer and lymph node metastasis, lymph node metastasis occurred from SM infiltration over 1,000 $\mu \mathrm{m}$. Therefore, in pathological tissue obtained by endoscopic resection, risk assessment is performed by measuring the depth of invasion $(\mu \mathrm{m})$ [63]. Based on the guideline of Japanese Society for Cancer of the Colon and Rectum (JSCCR), the depth of SM invasion is measured from the muscularis mucosa to the deepest point of invasion $[19,64]$. If the muscularis mucosa is destroyed by cancer invasion, the distance is measured from the cancer surface. However, there are also claims that measurements should be made with reference to an imaginary line connecting the extension of the intact muscularis mucosa [65].

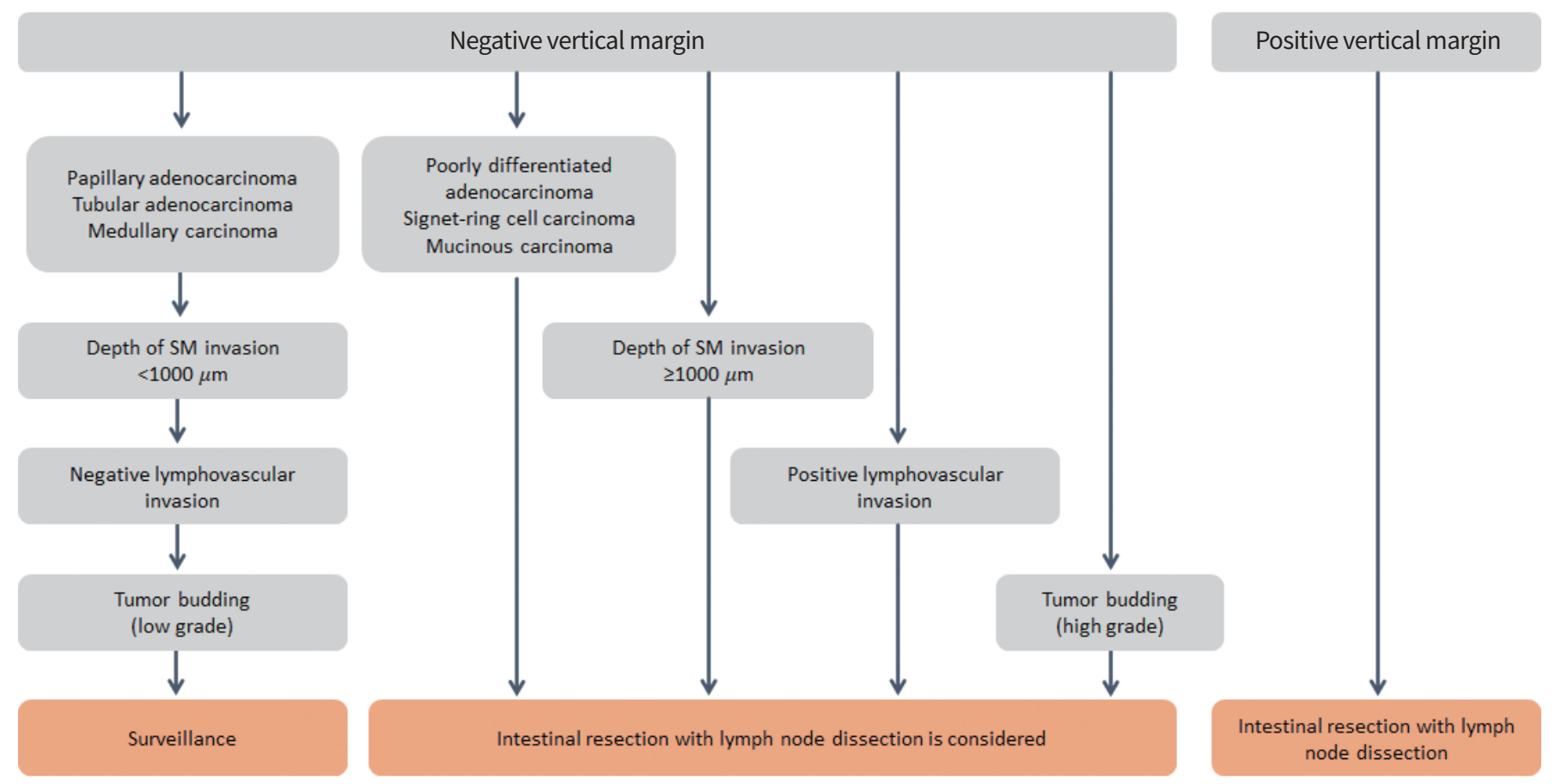

Fig. 1. Treatment strategies for pT1 submucosal (SM) cancer after endoscopic resection in the Japanese guideline for colorectal cancer treatment. Adapted from Hashiguchi et al. [19], according to the Creative Commons License. 
Resection margin involvement of cancer cells is the most important factor leading to the oncological failure of local excision. Delicated efforts to secure a sufficient resection margin should not be neglected for successful local excision with safe en bloc resection. A full-thickness resection is performed to include thick perirectal fat to ensure that the deep resection margin is $3 \mathrm{~mm}$ or more. However, the standard for safe resection margins in local excision remains unclear. Currently, there are various cut-offs, such as 1 and $2 \mathrm{~mm}$, and negative cancer cells with a resected margin [21].

Moreover, if the mesorectal fascia is exposed during local excision, inflammation and fibrosis may occur, which may negatively affect additional radical resection. When performing additional TME after local excision, the quality of the mesorectum deteriorates due to mesorectal fascia adhesion and fibrosis, which can lead to incomplete TME [66]. In cases in which it is difficult to distinguish cancer invasion or severe adhesions with the levator ani muscle or anal sphincter muscle, APR can be performed. Therefore, when implementing local excision, it is necessary not to damage the mesorectal fascia when considering TME.

\section{ALTERNATIVE STRATEGY FOR T1 HIGH RISK AND T2 ERC}

In the histologic examination performed after local excision, the following risk factors increase the possibility of lymph node metastasis: positive resection margin, poorly differentiated or mucinous adenocarcinoma, deep SM invasion ( $>1,000$ $\mu \mathrm{m}), \mathrm{SM} 3$ invasion, lymphovascular invasion, and tumor budding (G2/3) [67]. Therefore, local excision alone is insufficient for the treatment of high-risk ERC. As an additional surgical option, complete TME is the gold standard treatment. However, since lymph node metastasis is not confirmed in $10 \%$ of pathological specimens after radical resection, this surgical treatment may constitute overtreatment for some patients. Therefore, in addition to the excellent oncological treatment of radical resection, surgery-related mortality, complications, and deterioration of QOL should be considered [20]. Furthermore, alternative treatment strategies can be discussed with each patient based on their comorbidities, life expectancy, and preference for organ preservation.

\section{Adjuvant CRT}

After local excision is performed in high-risk ERCs, adjuvant CRT is an additional treatment that can be used based on histologic risk factors. Adjuvant CRT was able to reduce the local recurrence rate in high-risk T1 and T2 ERCs [68]. In order to attain organ preservation, a combination of local excision and adjuvant CRT has been considered as an alternative method to radical resection in practice guidelines. In high-risk T1 rectal cancer, local recurrence after TME and adjuvant CRT after local excision were similar. However, in $\mathrm{T} 2$ rectal cancer, local recurrence was higher with adjuvant CRT than with radial resection [69]. Therefore, the need for additional adjuvant chemotherapy is an emerging modality for organ preservation in T2 rectal cancers [70]. There are still few studies on a protocol comprising adjuvant chemotherapy in addition to local excision and adjuvant CRT in patients with $\mathrm{T} 2$ tumor. In the National Comprehensive Cancer Network (NCCN) guidelines (Version 2.2021) [21], 5-fluorouracil, leucovorin, and oxaliplatin (FOLFOX), or capecitabine and oxaliplatin (CAPOX) can be considered for these patients. Despite the relatively high local recurrence rate, adjuvant CRT after local excision was still applied to patients who were unable to undergo or refused radical resection. The results of the previous studies and meta-analyses are shown in Table $3[68,69,71-$ 75].

Currently, a Dutch research group is conducting RCT for patients with T1-2 tumors with intermediate risk. In the multicentered randomized trial of radical surgery versus adjuvant CRT after local excision for ERC (A multi-centred randomised trial of radical surgery versus adjuvant chemoradiotherapy after local excision for early rectal cancer [TESAR] trial), patients with T1-2 tumors with intermediate risk were classified based on the following: T1 within $3 \mathrm{~cm}$ with one of the risk factors, 3 to $5-\mathrm{cm}$ sized T1 without risk factors, and T2 tumors within $3 \mathrm{~cm}$ without risk [76]. Therefore, the stratified risk factors included the polyp size, T stage, poor differentiation, deep SM invasion (SM3), and lymphovascular invasion. After the local excision and pathologic evaluation, randomization was performed for adjuvant CRT or completion TME. If no oncological difference is found between adjuvant CRT and completion TME in this ongoing study, it will enable sophisticated patient selection to adequately recommend adjuvant CRT after local excision in ERC. In particular, the safe use of local excision will be expanded for the evaluation of pathological risk factors for ERC, especially in medical societies where advanced endoscopic resection cannot be applied in clinical practice.

\section{Neoadjuvant CRT for ERC}

Neoadjuvant CRT in patients with stage I rectal cancer is considered an overtreatment. This is due to the fact that TME sur- 
PRECISION AND FUTURE MEDICINE

Gyung Mo Son, et al.

Table 3. Clinical studies of local excision with or without adjuvant chemoradiation therapy for early rectal cancer

\begin{tabular}{|c|c|c|c|c|c|c|c|c|c|}
\hline Study & Year & Country & Design & $\begin{array}{l}\text { No. of } \\
\text { patient }\end{array}$ & Stage & $\begin{array}{l}\text { No. of } \\
\text { treatment }\end{array}$ & LR & DFS & os \\
\hline Chakravarti et al. [71] & 1999 & USA & $\begin{array}{l}\text { Retrospective } \\
\text { study }\end{array}$ & 99 & урT1-т2 & $\begin{array}{c}\text { LE (52) } \\
\text { LE+CRT (47) }\end{array}$ & $\begin{array}{r}12(24) \\
5(10)\end{array}$ & $\begin{array}{l}38(66) \\
35(74)\end{array}$ & $77(78)$ \\
\hline Wentworth et al. [72] & 2005 & USA & $\begin{array}{l}\text { Retrospective } \\
\text { study }\end{array}$ & 125 & урT1-т2 & $\mathrm{LE} \pm \mathrm{CRT}$ & 20 & $86(69)$ & $95(76)$ \\
\hline Han et al. [73] & 2010 & China & $\begin{array}{l}\text { Retrospective } \\
\text { study }\end{array}$ & 107 & pT1-T2 & $\begin{array}{c}\mathrm{LE}(25) \\
\mathrm{LE}+\mathrm{CRT}(82)\end{array}$ & $14(13)$ & $86(80)$ & $86(80)$ \\
\hline $\begin{array}{l}\text { Borstlap et al. [69] } \\
\text { (Ongoing) }\end{array}$ & 2016 & Netherland & $\begin{array}{l}\text { Multicentre } \\
\text { randomized } \\
\text { trial, TESAR }\end{array}$ & 302 & pT1-T2 & $\begin{array}{l}\mathrm{LE}+\mathrm{CRT} \\
\mathrm{LE}+\mathrm{CTME}\end{array}$ & & & \\
\hline Jeong et al. [74] & 2016 & Korea & $\begin{array}{l}\text { Prospective } \\
\text { study }\end{array}$ & 83 & pT1-T2 & $\mathrm{LE}+\mathrm{CRT}$ & $3(4)$ & $75(90)$ & $79(95)$ \\
\hline Lee et al. [75] & 2017 & UK & Meta-analysis & 4,822 & pT2NOMO & $\begin{array}{c}\text { TME }(4,367) \\
\text { LE+CRT }(242) \\
\text { NACRT+LE (213) }\end{array}$ & - & - & $\begin{array}{r}3,362(77) \\
194(80) \\
162(76)\end{array}$ \\
\hline Cutting et al. [68] & 2018 & UK & Meta-analysis & 804 & pT1-T3 & $\begin{array}{c}\text { LE } \\
\text { LE+CRT }\end{array}$ & $101(13)$ & $708(88)$ & $614(76)$ \\
\hline
\end{tabular}

Values are presented as number (\%).

LR, local recurrence; DFS, disease-free survival rate; OS, overall survival; LE, local excision; CRT, adjuvant chemoradiation therapy; TESAR, a multicentred randomised trial of radical surgery versus adjuvant chemoradiotherapy after local excision for early rectal cancer; cTME, completion total mesorectal excision; TME, total mesorectal excision; NACRT, neoadjuvant chemoradioation therapy.

gery alone is able to achieve excellent oncological results. Pathologic complete remission ( $\mathrm{pCR}$ ) after neoadjuvant CRT in locally advanced rectal cancer occurs in approximately $10 \%$ of patients $[77,78]$. Patients who achieve $\mathrm{pCR}$ show very good oncological results. Therefore, pCR obtained by neoadjuvant CRT is considered an important surrogate for the prognosis of locally advanced rectal cancer [79]. Habr-Gama et al. [80] reported that after neoadjuvant CRT in patients with rectal cancer, intensive surveillance was continued for up to 12 months if there was no tumor regrowth in patients with clinical complete remission ( $\mathrm{CCR}$ ), and organ preservation was possible in approximately $80 \%$ of patients. Additionally, the oncological results were comparable to those of patients with complete TME [80]. After it was shown that neoadjuvant CRT could yield more pCR with small tumor size and decreased depth of invasion, new hopes for organ preservation were extended to the field of ERC $[81,82]$.

If $\mathrm{pCR}$ is obtained through neoadjuvant CRT, improved oncological results can be expected even with organ preservation therapy [83]. However, pCR and cCR were not consistent with each other [84]. Indications for CCR typically include no mucosal mass on digital rectal examination, no mucosal abnormalities on endoscopy, and no cancerous lesions in the rectal wall on pelvic MRI. However, even if all three conditions are satisfied for CCR, $27 \%$ of CCR cases exhibit viable cancer cells or clusters on histopathological examination after local excision or radical resection. Conversely, in many cases, mucosal abnormalities or shallow ulcers can be confirmed by $\mathrm{PCR}$. This is due to the fact that after radiotherapy, mucosal edema, inflammation, fibrotic reaction, and mucinous pool of necrotic cancer tissue can mistakenly indicate the presence of a remnant tumor. In the Magnetic Resonance Imaging and Rectal Cancer European Equivalence Study (MERCURY) study, it was revealed that the tumor regression grade can be evaluated based on the fact that fibrotic tissue shows a low signal in the $\mathrm{T} 2$ weighted image and that viable cancer cells show a high signal in the diffusion-weighted image [85]. However, cCR does not necessarily guarantee a pCR. Therefore, the only way to evaluate $\mathrm{PCR}$ is to confirm the presence of viable cancer cells through pathological examination by performing local excision.

Currently, important RCTs or prospective studies are underway to attempt organ preservation using neoadjuvant CRT for ERC (Table 4) [16-18,86-89]. Lezoche et al. [86] performed a prospective multicenter study with a researcher's conference in Urbino, Italy. Neoadjuvant CRT was performed on 100 pa- 
PRECISION AND FUTURE MIEDICINE

Treatment strategy for early rectal cancer

Table 4. Prospective clinical trials for neoadjuvant chemoradiation therapy with local excision for early rectal cancer

\begin{tabular}{|c|c|c|c|c|c|c|c|c|c|c|c|c|}
\hline Trial name & Study & Year & Country & Design & $\begin{array}{l}\text { No. of } \\
\text { patient }\end{array}$ & Stage & No. of treatment & CR & OP & LR & DFS & OS \\
\hline URBINO & $\begin{array}{l}\text { Lezoche } \\
\text { et al. [86] }\end{array}$ & 2012 & Italy & $\begin{array}{l}\text { Multicenter, } \\
\text { prospective } \\
\text { randomized } \\
\text { trial }\end{array}$ & 100 & $\mathrm{CT} 2 \mathrm{NO}$ & $\begin{array}{l}\text { NACRT+TEM (50) } \\
\text { NACRT+TME (50) }\end{array}$ & - & $\begin{array}{c}50(100) \\
0(0)\end{array}$ & $\begin{array}{l}4(8) \\
3(6)\end{array}$ & $\begin{array}{l}45(89) \\
47(94)\end{array}$ & $\begin{array}{l}36(72) \\
40(80)\end{array}$ \\
\hline $\begin{array}{c}\text { ACOSOG } \\
\text { Z6041 }\end{array}$ & $\begin{array}{l}\text { Garcia } \\
\text { et al. [87] }\end{array}$ & 2015 & USA & $\begin{array}{l}\text { Single-arm, } \\
\text { open label } \\
\text { phase II trial }\end{array}$ & 79 & CT2NO & NACRT+LE $\pm c T M E$ & - & $72(91)$ & $3(4)$ & $70(88)$ & $75(95)$ \\
\hline $\begin{array}{r}\text { STAR-TREC } \\
\text { (ongoing) }\end{array}$ & $\begin{array}{r}\text { Rombouts } \\
\text { et al. [16] }\end{array}$ & 2017 & $\begin{array}{c}\text { UK, } \\
\text { Netherlands, } \\
\text { Denmark }\end{array}$ & $\begin{array}{l}\text { Multicenter, } \\
\text { randomized } \\
\text { phase III study }\end{array}$ & 120 & $\begin{array}{l}\text { cT1- } \\
\text { 3bN0 }\end{array}$ & $\begin{array}{c}\text { TME } \\
\text { NACRT } \pm \text { TEM } \pm \text { cTME }\end{array}$ & & & & & \\
\hline POLISH & $\begin{array}{l}\text { Wawok } \\
\text { et al. [88] }\end{array}$ & 2018 & Poland & $\begin{array}{l}\text { Prospective } \\
\text { randomized } \\
\text { phase III study }\end{array}$ & 51 & $\begin{array}{l}\text { CT1- } \\
3 \mathrm{~N} 0\end{array}$ & 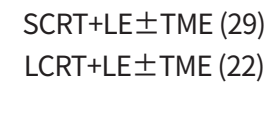 & $15(29)$ & $\begin{array}{l}25(66) \\
20(86)\end{array}$ & $\begin{array}{c}10(35) \\
1(5)\end{array}$ & $\begin{array}{l}10(34) \\
18(81)\end{array}$ & $\begin{array}{l}14(47) \\
19(86)\end{array}$ \\
\hline CARTS & $\begin{array}{l}\text { Stijns } \\
\text { et al. [17] }\end{array}$ & 2019 & Netherlands & $\begin{array}{l}\text { Multicenter } \\
\text { phase II } \\
\text { feasibility } \\
\text { study }\end{array}$ & 55 & $\begin{array}{l}\text { cT1- } \\
3 \mathrm{~N} 0\end{array}$ & $\begin{array}{c}\text { NACRT (+LE } \pm \text { TME) or } \\
\text { TME }\end{array}$ & - & $35(74)$ & $4(8)$ & $42(82)$ & $42(82)$ \\
\hline GRECCAR 2 & $\begin{array}{l}\text { Rullier } \\
\text { et al. [18] }\end{array}$ & 2020 & France & $\begin{array}{l}\text { Multicentre, } \\
\text { phase III } \\
\text { randomized } \\
\text { trial }\end{array}$ & 145 & $\begin{array}{l}\text { CT2- } \\
3 \mathrm{NO}\end{array}$ & $\begin{array}{c}\text { NACRT+LE } \pm \text { TME (74) } \\
\text { NACRT+TME (71) }\end{array}$ & - & $\begin{array}{l}47(64) \\
11(15)\end{array}$ & $\begin{array}{l}5(7) \\
5(7)\end{array}$ & $\begin{array}{l}52(90) \\
52(72)\end{array}$ & $\begin{array}{l}63(84) \\
59(82)\end{array}$ \\
\hline TREC & $\begin{array}{l}\text { Bach } \\
\text { et al. [89] }\end{array}$ & 2021 & UK & $\begin{array}{l}\text { Randomized, } \\
\text { open-label } \\
\text { feasibility } \\
\text { study }\end{array}$ & 55 & $\begin{array}{l}\text { cT1- } \\
2 \mathrm{~N} 0\end{array}$ & $\begin{array}{l}\text { SCRT+LE (27) } \\
\text { TME (28) }\end{array}$ & $\begin{array}{l}8(30) \\
0(0)\end{array}$ & $\begin{array}{c}19(70) \\
1(3)\end{array}$ & $\begin{array}{l}3(11) \\
0(0)\end{array}$ & $\begin{array}{l}24(88) \\
26(93)\end{array}$ & $\begin{array}{l}21(76) \\
24(85)\end{array}$ \\
\hline
\end{tabular}

Values are presented as number (\%).

CR, completed response; OP, organ preservation; LR, local recurrence; DFS, disease-free survival rate; OS, overall survival; URBINO, randomized clinical trial of endoluminal locoregional resection versus laparoscopic total mesorectal excision for T2 rectal cancer after neoadjuvant therapy; NACRT, neoadjuvant chemoradiation therapy; TEM, transanal endoscopic microsurgery; TME, total mesorectal excision; ACOSOG, American College of Surgeons Oncology Group; LE, local excision; cTME, completion total mesorectal excision; STAR-TREC, Save the rectum by watchful waiting or TransAnal microsurgery following (chemo) Radiotherapy versus TME for early REctal Cancer; POLISH, preoperative radiotherapy and local excision of rectal cancer with immediate radical re-operation for poor responders; SCRT, short-course radiation therapy; LCRT, long-course chemoradiation therapy; CARTS, Transanal Endoscopic Microsurgery After Radiochemotherapy for Rectal Cancer study: a prospective, multicenter study; GRECCAR 2, organ preservation for rectal cancer: a prospective, randomised, open-label, multicentre, phase 3 trial; TREC, radical surgery versus organ preservation via short-course radiotherapy followed by transanal endoscopic microsurgery for early-stage rectal cancer: a randomised, open-label feasibility study.

tients with well-to-moderately differentiated (G1-2) T2 tumor with a relatively low risk of lymph node metastasis, less than $3 \mathrm{~cm}$; subsequently, TME or TEM were randomly administered to 50 patients. Consequently, the local recurrence rates were similar at $10 \%$ and $12 \%(P=0.606)$, respectively, and there was no statistical difference in cancer-related survival and overall survival rates. In this study, organ preservation was performed in ypT0-1 good responders (52\%) through neoadjuvant CRT and TEM. However, neoadjuvant CRT and TME in patients with cT2 may be overtreated compared to those treated with TME alone. Although this was a relatively small multicenter RCT study, it provided the first bridgehead of evidence that neoadjuvant CRT can be considered for organ preservation in ERC.

The American College of Surgeons Oncology Group (ACOSOG) Z6041 trial was a phase II single-arm multicenter prospective study conducted in the United States [90]. The subjects were patients with cT2NOMO diagnosed using MRI. First, neoadju- 
vant CRT was performed, and pathologic tumor regression was evaluated by local excision using TAE or TEM. In neoadjuvant CRT, intensive surveillance was performed in patients with good response (ypT0-2), and completion TME was performed within 4 weeks in patients with poor response (ypT3) or with resection margin involvement. Successful $p C R$ was achieved in $49 \%$ of patients, and most patients (94\%) showed a good response to ypT0-2. The 3-year local recurrence rate was only $4 \%$, and organ preservation was possible in $91 \%$ of the patients. In this study, the radiation dose was $54 \mathrm{~Gy}$, which was higher than the standard treatment, and 5-FU and oxaliplatin were used as radiosensitizers. However, radiation and 5-FU doses were reduced when patients had high-grade toxicities for high-dose CRT [87]. The ACOSOG Z6041 trial demonstrated that organ preservation could be achieved through neoadjuvant CRT in highly selected patients with CT2 ERC.

In France, the organ preservation for rectal cancer: a prospective, randomised, open-label, multicentre, phase 3 trial (GRECCAR) 2 study was conducted involving patients with CT2-3 low rectal cancer with a tumor size of less than $4 \mathrm{~cm}$ [18,91]. First, neoadjuvant CRT was performed, and TEM and TME were randomly assigned. In the TEM group, patients with ypT0-1 underwent intensive surveillance, and in patients with ypT2-3, complete TME was additionally performed. There was no statistical difference in long-term oncological outcomes between the two groups. A good response (ypT0-1) to CRT was achieved in 54\% of patients, which was slightly lower than that (ypT0-1) in ACOSOG Z6041, which was $63 \%$. These results may be due to differences in the target patient group and CRT dose and regimen. In this study, QOL was investigated for 12 months, and the $\mathrm{QOL}$ of the TEM group gradually worsened. If completion of TME was performed in the TEM group that had already received neoadjuvant CRT, treatment-related toxicities would accumulate, increasing morbidities, and affecting QOL deterioration. Local excision can be used to effectively evaluate the pathologic regression level of neoadjuvant CRT, which greatly aids in the decision of further treatment. However, local excision performed prior to the completion of TME may decrease the quality of the TME and lead to poor prognosis. Recently, if complete TME was performed early, within 4 weeks, the oncological results were similar to those of primary TME. Therefore, in the high-risk group requiring additional surgery, completion of TME should be performed as soon as possible, ideally within 4 weeks.

In patients with ERC, neoadjuvant CRT and additional TME may be obvious overtreatments. Therefore, it would be reasonable to compare the neoadjuvant CRT protocol with the standard treatment of primary TME in patients with ERC. In the UK, a study comparing the effects of neoadjuvant CRT and TEM with primary TME was conducted. In this randomized, open label feasibility study, they compared the effect of radical surgery versus organ preservation via short-course radiation therapy (SCRT) followed by TEM for ERC (TREC study) [89]. Patients with cT1-2 rectal cancer were randomly assigned to a primary TME group and a SCRT+TEM group. A unique feature of this study was that a non-randomized track was maintained, omitting randomization when primary TME was clearly needed or the patient strongly required organ preservation. Interestingly, $90 \%$ of patients with ERC opted for organ preservation in a non-randomized track. In the SCRT+TEM group, completion TME was performed within 8 weeks for tumors greater than $3 \mathrm{~cm}$, positive resection margins ( $<1 \mathrm{~mm}$ ), poor differentiation, lymphovascular invasion, SM3 invasion, and unfavorable responses more than PT2. In this study, the CCR frequency of SCRT was $30 \%$, and organ preservation was possible in $70 \%$ of patients. The SCRT+TEM group showed favorable results for bowel function and QOL, and oncological outcomes comparable to those of the primary TME group.

In the Netherlands, prospective multicenter phase II feasibility study was performed for evaluating long-term oncologic and functional outcomes of CRT followed by organ-sparing TEM for distal rectal cancer on patients with CT1-3 as Transanal Endoscopic Microsurgery After Radiochemotherapy for Rectal Cancer study (CARTS). Neoadjuvant CRT was performed, and magnetic resonance regression was used to classify good responders (ycT0-2) and poor responders (yсT3-4). Good responders underwent local excision, intensive surveillance was performed for ypT0-1, and completion TME was performed for ypT2-3. Poor responders underwent primary TME $[17,92]$. In this study protocol, organ preservation was achieved in $74 \%$ of patients, and local recurrence was achieved in $7.7 \%$.

After two small-scale RCTs were successfully conducted in Europe, the TREC (UK) and CARTS (Netherland) study groups decided to merge these two protocols and proceed with a three-arm RCT study to Save the rectum by watchful waiting or TransAnal microsurgery following (chemo) Radiotherapy versus TME for early REctal Cancer (STAR-TREC) [16]. In this ongoing study, patients with cT1-3 rectal cancer smaller than $4 \mathrm{~cm}$ were randomized to one of three treatment groups: primary TME, neoadjuvant CRT, and neoadjuvant SCRT. The re- 
sponse to CRT was evaluated based on the degree of tumor downsizing using endoscopy and pelvic MRI. In good responders with a significant reduction in tumor size, patients with cCR status up to 20 weeks after CRT continued active surveillance with a 'watch and wait' strategy. TEM was performed for incomplete tumor response, in which tumor downsizing was achieved in more than $50 \%$ of patients; however, tumors were still observed. For poor response with little tumor downsizing, a primary TME was performed. Currently, the STARTREC trial group is conducting phase II research to evaluate the feasibility of patient enrollment for large-scale multicenter three-arm RCTs (Fig. 2). If patient enrollment is adequately maintained, a phase III STAR-TREC trial will be continued.

In these various RCTs, CCR via neoadjuvant CRT was obtained in $60 \%$ to $70 \%$ of ERCs [14]. Moreover, organ preservation could be safely provided to a significant number of pa- tients with ERC who had a good response to neoadjuvant CRT. However, the criteria for a good response to neoadjuvant CRT differ among studies. In most studies, ypT0-1 was used; however, in the ACOSOG Z6041 study, ypT2 was included for the group of good responders. Therefore, different studies have different strategies regarding whether completion of TME or active surveillance is needed in patients with ypT2. Moreover, it remains unclear whether local excision or primary TME should be performed in patients with ycT2 who have received neoadjuvant CRT. Therefore, the criteria to determine whether a good response to neoadjuvant CRT is achieved remain controversial.

In the future, if ongoing or planned RCTs demonstrate the safety of a more advanced treatment strategy, the current treatment strategy for ERC could be significantly modified for organ preservation. However, to date, neoadjuvant CRT and organ preservation strategies for ERC retain a risk for

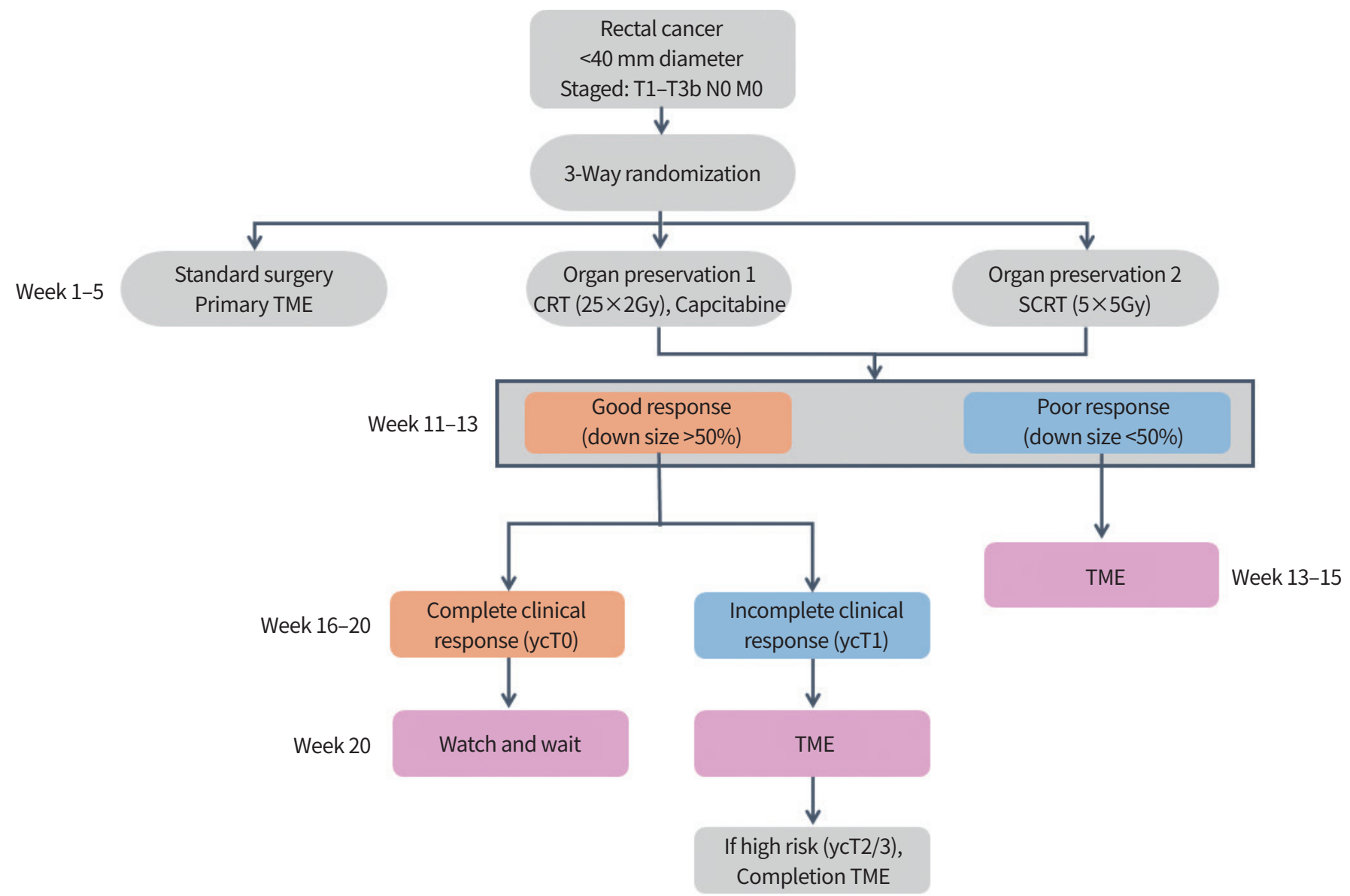

Fig. 2. Flow chart of the Save the rectum by watchful waiting or TransAnal microsurgery following (chemo) Radiotherapy versus TME for early REctal Cancer (STAR-TREC) trial as multicenter international randomized, three-arm parallel, phase II feasibility study. Adapted from Rombouts et al. [16], according to the Creative Commons License. TME, total mesorectal excision; SCRT, short-course radiation therapy; CRT, chemoradiation therapy; TEM, transanal endoscopic microsurgery. 
overtreatment and increased toxicity. Therefore, neoadjuvant CRT in ERCs can only be restricted to a clinical trial setting. If radical resection is unbearable for the patient or is refused, conservative treatment, including local excision+CRT, may be suggested as an alternative treatment strategy.

\section{SUMMARY}

The treatment of ERC is continuously evolving in an effort to achieve organ preservation in rectal cancer. Accurate preoperative diagnosis is the most critical point in selecting an appropriate treatment strategy to obtain the best oncological outcome. With the development of endoscopic evaluation, the possibility of deep SM invasion can be predicted using $\mathrm{NBI}, \mathrm{MCE}$, and endoscopic ultrasonography. If deep mucosal invasion is suspected on endoscopic evaluation, only targeted biopsy should be performed, and surgical resection should be considered. Pelvic MRI can be used to evaluate lymph node metastasis. However, TME as a radical resection may be the gold standard treatment. Adjuvant CRT may be considered in patients who are unsusceptible or refuse radical resection if a high risk of lymph node metastasis is identified after local excision. However, adjuvant CRT has a higher risk of local recurrence than radical resection, and this should be discussed with the patient. If the tumor is small (within 3 to $4 \mathrm{~cm}$ ), organ preservation should be performed with neoadjuvant CRT. However, it should only be applied in clinical trials.

\section{CONCLUSION}

The national cancer screening program increased the ERC detection rate. Multidisciplinary treatment strategies for ERC are still evolving. Based on RCTs, a multimodal treatment strategy for patient-tailored therapy needs to be established to achieve the goal of a safe oncological cure and organ preservation with favorable QOL for patients with ERC.

\section{CONFLICTS OF INTEREST}

No potential conflict of interest relevant to this article was reported.

\section{ACKNOWLEDGMENTS}

The Authors appreciate the medical staffs of the Gastroenterology Center, Pusan National University Yangsan Hospital,
Yangsan, Korea.

\section{ORCID}

$\begin{array}{ll}\text { Gyung Mo Son } & \text { https://orcid.org/0000-0002-8861-6293 } \\ \text { In Young Lee } & \text { https://orcid.org/0000-0001-5954-6188 } \\ \text { Sung Hwan Cho } & \text { https://orcid.org/0000-0003-0451-5987 } \\ \text { Byung-Soo Park } & \text { https://orcid.org/0000-0001-7782-5551 } \\ \text { Hyun Sung Kim } & \text { https://orcid.org/0000-0002-7607-4597 } \\ \text { Su Bum Park } & \text { https://orcid.org/0000-0003-1573-2792 } \\ \text { Hyung Wook Kim } & \text { https://orcid.org/0000-0002-2444-0591 } \\ \text { Sang Bo Oh } & \text { https://orcid.org/0000-0001-7257-0350 } \\ \text { Tae Un Kim } & \text { https://orcid.org/0000-0003-1017-6926 } \\ \text { Dong Hoon Shin } & \text { https://orcid.org/0000-0002-4980-9295 }\end{array}$

\section{AUTHOR CONTRIBUTIONS}

Conception or design: GMS.

Acquisition, analysis, or interpretation of data: GMS, IYL, SHC, BSP, HSK, SBO, TUK, DHS.

Drafting the work or revising: GMS, IYL, SHC, BSP, SBP.

Final approval of the manuscript: GMS, HWK.

\section{REFERENCES}

1. Choi KH, Song JH, Jang HS, Kim SH, Lee JH. Current trends in the quality assessment of colorectal cancer practice and treatment in South Korea during 2012-2017. Cancer Res Treat 2021;53:487-96.

2. Hyun JH, Alhanafy MK, Park HC, Park SM, Park SC, Sohn DK, et al. Initial local excision for clinical T1 rectal cancer showed comparable overall survival despite high local recurrence rate: a propensity-matched analysis. Ann Coloproctol 2021 Oct 6 [Epub]. https://doi.org/10.3393/ac. 2021.00479.0068.

3. Kim MJ, Jeong SY, Park JW, Ryoo SB, Cho SS, Lee KY, et al. Oncologic outcomes in patients who undergo neoadjuvant chemoradiotherapy and total mesorectal excision for locally advanced rectal cancer: a 14-year experience in a single institution. Ann Coloproctol 2019;35:83-93.

4. Hur H, Oh CM, Won YJ, Oh JH, Kim NK. Characteristics and survival of Korean patients with colorectal cancer based on data from the Korea Central Cancer Registry data. Ann Coloproctol 2018;34:212-21.

5. Lee SM, Shin JS. Colorectal cancer in octogenarian and nonagenarian patients: clinicopathological features and survivals. Ann Coloproctol 2020;36:323-9. 
6. Lam D, Jones O. Changes to gastrointestinal function after surgery for colorectal cancer. Best Pract Res Clin Gastroenterol 2020;48-49:101705.

7. Eldamshety O, Kotb S, Khater A, Roshdy S, Elashry M, Zahi MS, et al. Early and late functional outcomes of anal sphinctersparing procedures with total mesorectal excision for anorectal adenocarcinoma. Ann Coloproctol 2020; 36:148-54.

8. Cura Pales CG, An S, Cruz JP, Kim K, Kim Y. Postoperative bowel function after anal sphincter-preserving rectal cancer surgery: risks factors, diagnostic modalities, and management. Ann Coloproctol 2019;35:160-6.

9. Sao Juliao GP, Celentano JP, Alexandre FA, Vailati BB. Local excision and endoscopic resections for early rectal cancer. Clin Colon Rectal Surg 2017;30:313-23.

10. Park IJ, Lee JL, Yoon YS, Kim CW, Lim SB, Yu CS, et al. Oncologic outcomes of organ preserving approaches in patients with rectal cancer treated with preoperative chemoradiotherapy. Ann Coloproctol 2019;35:65-71.

11. Chavda V, Siaw O, Chaudhri S, Runau F. Management of early rectal cancer; current surgical options and future direction. World J Gastrointest Surg 2021;13:655-67.

12. Marijnen CA. Organ preservation in rectal cancer: have all questions been answered? Lancet Oncol 2015;16:e13-22.

13. You YN, Hardiman KM, Bafford A, Poylin V, Francone TD, Davis K, et al. The American Society of Colon and Rectal Surgeons clinical practice guidelines for the management of rectal cancer. Dis Colon Rectum 2020;63:1191-222.

14. Franke AJ, Skelton WP 4th, George TJ, Iqbal A. A comprehensive review of randomized clinical trials shaping the landscape of rectal cancer therapy. Clin Colorectal Cancer 2021;20:1-19.

15. Morino M, Risio M, Bach S, Beets-Tan R, Bujko K, Panis Y, et al. Early rectal cancer: the European Association for Endoscopic Surgery (EAES) clinical consensus conference. Surg Endosc 2015;29:755-73.

16. Rombouts A, Al-Najami I, Abbott NL, Appelt A, Baatrup G, Bach S, et al. Can we Save the rectum by watchful waiting or TransAnal microsurgery following (chemo) Radiotherapy versus Total mesorectal excision for early REctal Cancer (STAR-TREC study)?: protocol for a multicentre, randomised feasibility study. BMJ Open 2017;7:e019474.

17. Stijns R, de Graaf E, Punt C, Nagtegaal ID, Nuyttens J, van Meerten $\mathrm{E}$, et al. Long-term oncological and functional outcomes of chemoradiotherapy followed by organ-sparing transanal endoscopic microsurgery for distal rectal cancer: the CARTS study. JAMA Surg 2019;154:47-54.
18. Rullier E, Vendrely V, Asselineau J, Rouanet P, Tuech JJ, Valverde A, et al. Organ preservation with chemoradiotherapy plus local excision for rectal cancer: 5-year results of the GRECCAR 2 randomised trial. Lancet Gastroenterol Hepatol 2020;5:465-74.

19. Hashiguchi Y, Muro K, Saito Y, Ito Y, Ajioka Y, Hamaguchi T, et al. Japanese Society for Cancer of the Colon and Rectum (JSCCR) guidelines 2019 for the treatment of colorectal cancer. Int J Clin Oncol 2020;25:1-42.

20. Russo S, Anker CJ, Abdel-Wahab M, Azad N, Das P, Dragovic J, et al. Executive summary of the American Radium Society appropriate use criteria for local excision in rectal cancer. Int J Radiat Oncol Biol Phys 2019;105:97793.

21. National Comprehensive Cancer Network. NCCN Clinical Practice Guidelines in Oncology: Rectal Cancer ver2.2021 [Internet]. Plymouth Meeting (PA): NCCN; 2021 [cited 2021 Sec 9]. Available from: https://www.nccn.org/guidelines/ guidelines-detail?category $=1 \& i d=1461$.

22. Glynne-Jones R, Wyrwicz L, Tiret E, Brown G, Rodel C, Cervantes A, et al. Rectal cancer: ESMO clinical practice guidelines for diagnosis, treatment and follow-up. Ann Oncol 2017;28(Suppl 4):iv22-40.

23. Lee KY, Shin JK, Park YA, Yun SH, Huh JW, Cho YB, et al. Transanal endoscopic and transabdominal robotic total mesorectal excision for mid-to-low rectal cancer: comparison of short-term postoperative and oncologic outcomes by using a case-matched analysis. Ann Coloproctol 2018;34:29-35.

24. Allaix ME, Arezzo A, Morino M. Transanal endoscopic microsurgery for rectal cancer: T1 and beyond? An evidence-based review. Surg Endosc 2016;30:4841-52.

25. Dulskas A, Kilius A, Petrulis K, Samalavicius NE. Transanal endoscopic microsurgery for patients with rectal tumors: a single institution's experience. Ann Coloproctol 2017; 33:23-7.

26. Devane LA, Burke JP, Kelly JJ, Albert MR. Transanal minimally invasive surgery for rectal cancer. Ann Gastroenterol Surg 2020;5:39-45.

27. Stipa F, Tierno SM, Russo G, Burza A. Trans-anal minimally invasive surgery (TAMIS) versus trans-anal endoscopic microsurgery (TEM): a comparative case-control matchedpairs analysis. Surg Endosc 2022;36:2081-6.

28. Lee SG, Russ AJ, Casillas MA Jr. Laparoscopic transanal minimally invasive surgery (L-TAMIS) versus robotic TAMIS (R-TAMIS): short-term outcomes and costs of a comparative study. Surg Endosc 2019;33:1981-7. 
29. Liu S, Kelley SR, Behm KT. Single-port robotic transanal minimally invasive surgery (SPR-TAMIS) approach to local excision of rectal tumors. Tech Coloproctol 2021;25: 229-34.

30. Jang JH, Kim CN. Robotic total mesorectal excision for rectal cancer: current evidences and future perspectives. Ann Coloproctol 2020;36:293-303.

31. Stornes T, Wibe A, Nesbakken A, Myklebust TA, Endreseth $\mathrm{BH}$. National early rectal cancer treatment revisited. Dis Colon Rectum 2016;59:623-9.

32. Hwang Y, Yoon YS, Bong JW, Choi HY, Song IH, Lee JL, et al. Long-term transanal excision outcomes in patients with T1 rectal cancer: comparative analysis of radical resection. Ann Coloproctol 2019;35:194-201.

33. You YN, Baxter NN, Stewart A, Nelson H. Is the increasing rate of local excision for stage I rectal cancer in the United States justified?: a nationwide cohort study from the National Cancer Database. Ann Surg 2007;245:726-33.

34. Bach SP, Hill J, Monson JR, Simson JN, Lane L, Merrie A, et al. A predictive model for local recurrence after transanal endoscopic microsurgery for rectal cancer. Br J Surg 2009; 96:280-90.

35. Oh BY, Yun HR, Kim SH, Yun SH, Kim HC, Lee WY, et al. Features of late recurrence following transanal local excision for early rectal cancer. Dis Colon Rectum 2015;58: 1041-7.

36. Backes Y, de Vos Tot Nederveen Cappel WH, van Bergeijk J, Ter Borg F, Schwartz MP, Spanier B, et al. Risk for incomplete resection after macroscopic radical endoscopic resection of T1 colorectal cancer: a multicenter cohort study. Am J Gastroenterol 2017;112:785-96.

37. Carrara A, Mangiola D, Pertile R, Ricci A, Motter M, Ghezzi $\mathrm{G}$, et al. Analysis of risk factors for lymph nodal involvement in early stages of rectal cancer: when can local excision be considered an appropriate treatment? Systematic review and meta-analysis of the literature. Int J Surg Oncol 2012;2012:438450.

38. Resch A, Langner C. Risk assessment in early colorectal cancer: histological and molecular markers. Dig Dis 2015; 33:77-85.

39. Beaton C, Twine CP, Williams GL, Radcliffe AG. Systematic review and meta-analysis of histopathological factors influencing the risk of lymph node metastasis in early colorectal cancer. Colorectal Dis 2013;15:788-97.

40. Brown G, Richards CJ, Bourne MW, Newcombe RG, Radcliffe AG, Dallimore NS, et al. Morphologic predictors of lymph node status in rectal cancer with use of high-spa- tial-resolution MR imaging with histopathologic comparison. Radiology 2003;227:371-7.

41. Kim JH, Beets GL, Kim MJ, Kessels AG, Beets-Tan RG. High-resolution MR imaging for nodal staging in rectal cancer: are there any criteria in addition to the size? Eur J Radiol 2004;52:78-83.

42. Bipat S, Glas AS, Slors FJ, Zwinderman AH, Bossuyt PM, Stoker J. Rectal cancer: local staging and assessment of lymph node involvement with endoluminal US, CT, and MR imaging. A meta-analysis. Radiology 2004;232:77383.

43. Lahaye MJ, Engelen SM, Nelemans PJ, Beets GL, van de Velde CJ, van Engelshoven JM, et al. Imaging for predicting the risk factors: the circumferential resection margin and nodal disease. Of local recurrence in rectal cancer: a meta-analysis. Semin Ultrasound CT MR 2005;26:259-68.

44. Al-Sukhni E, Milot L, Fruitman M, Beyene J, Victor JC, Schmocker S, et al. Diagnostic accuracy of MRI for assessment of T category, lymph node metastases, and circumferential resection margin involvement in patients with rectal cancer: a systematic review and meta-analysis. Ann Surg Oncol 2012;19:2212-23.

45. Wang C, Zhou Z, Wang Z, Zheng Y, Zhao G, Yu Y, et al. Patterns of neoplastic foci and lymph node micrometastasis within the mesorectum. Langenbecks Arch Surg 2005; 390:312-8.

46. Aarons CB, Shanmugan S, Bleier JI. Management of malignant colon polyps: current status and controversies. World J Gastroenterol 2014;20:16178-83.

47. Tanaka S, Kashida H, Saito Y, Yahagi N, Yamano H, Saito S, et al. JGES guidelines for colorectal endoscopic submucosal dissection/endoscopic mucosal resection. Dig Endosc 2015;27:417-34.

48. Facciorusso A, Antonino M, Di Maso M, Barone M, Muscatiello N. Non-polypoid colorectal neoplasms: classification, therapy and follow-up. World J Gastroenterol 2015;21: 5149-57.

49. Sano Y, Tanaka S, Kudo SE, Saito S, Matsuda T, Wada Y, et al. Narrow-band imaging (NBI) magnifying endoscopic classification of colorectal tumors proposed by the Japan NBI Expert Team. Dig Endosc 2016;28:526-33.

50. Wang Y, Li WK, Wang YD, Liu KL, Wu J. Diagnostic performance of narrow-band imaging international colorectal endoscopic and Japanese narrow-band imaging expert team classification systems for colorectal cancer and precancerous lesions. World J Gastrointest Oncol. 2021 15; 13:58-68. 
51. Backes Y, Schwartz MP, Ter Borg F, Wolfhagen F, Groen JN, de Vos Tot Nederveen Cappel WH, et al. Multicentre prospective evaluation of real-time optical diagnosis of T1 colorectal cancer in large non-pedunculated colorectal polyps using narrow band imaging (the OPTICAL study). Gut 2019;68:271-9.

52. Puig I, Lopez-Ceron M, Arnau A, Rosinol O, Cuatrecasas M, Herreros-de-Tejada A, et al. Accuracy of the narrow-band imaging international colorectal endoscopic classification system in identification of deep invasion in colorectal polyps. Gastroenterology 2019;156:75-87.

53. Backes Y, Moss A, Reitsma JB, Siersema PD, Moons LM. Narrow band imaging, magnifying chromoendoscopy, and gross morphological features for the optical diagnosis of T1 colorectal cancer and deep submucosal invasion: a systematic review and meta-analysis. Am J Gastroenterol 2017;112:54-64.

54. Tanaka S, Hayashi N, Oka S, Chayama K. Endoscopic assessment of colorectal cancer with superficial or deep submucosal invasion using magnifying colonoscopy. Clin Endosc 2013;46:138-46.

55. Kawaguti FS, Franco MC, Martins BC, Segateli V, Marques $\mathrm{C}$, Nahas C, et al. Role of magnification chromoendoscopy in the management of colorectal neoplastic lesions suspicious for submucosal invasion. Dis Colon Rectum 2019;62:422-8.

56. Emmanuel A, Lapa C, Ghosh A, Gulati S, Burt M, Hayee B, et al. Multimodal endoscopic assessment guides treatment decisions for rectal early neoplastic tumors. Dis CoIon Rectum 2020;63:326-35.

57. Kikuchi R, Takano M, Takagi K, Fujimoto N, Nozaki R, Fujiyoshi T, et al. Management of early invasive colorectal cancer. Risk of recurrence and clinical guidelines. Dis Colon Rectum 1995;38:1286-95.

58. Bisschops R, East JE, Hassan C, Hazewinkel Y, Kaminski MF, Neumann $\mathrm{H}$, et al. Advanced imaging for detection and differentiation of colorectal neoplasia: European Society of Gastrointestinal Endoscopy (ESGE) Guideline. Update 2019. Endoscopy 2019;51:1155-79.

59. Richards CH, Ventham NT, Mansouri D, Wilson M, Ramsay $G$, Mackay $C D$, et al. An evidence-based treatment algorithm for colorectal polyp cancers: results from the Scottish Screen-detected Polyp Cancer Study (SSPoCS). Gut 2018;67:299-306.

60. Vleugels J, Koens L, Dijkgraaf M, Houwen B, Hazewinkel Y, Fockens $\mathrm{P}$, et al. Suboptimal endoscopic cancer recognition in colorectal lesions in a national bowel screening pro- gramme. Gut 2020;69:977-80.

61. Takamaru H, Saito Y, Sekiguchi M, Yamada M, Sakamoto T, Matsuda T, et al. Endoscopic resection before surgery does not affect the recurrence rate in patients with highrisk T1 colorectal cancer. Clin Transl Gastroenterol 2021; 12:e00336.

62. Overwater A, Kessels K, Elias SG, Backes Y, Spanier B, Seerden T, et al. Endoscopic resection of high-risk T1 colorectal carcinoma prior to surgical resection has no adverse effect on long-term outcomes. Gut 2018;67:284-90.

63. Kitajima K, Fujimori T, Fujii S, Takeda J, Ohkura Y, Kawamata $\mathrm{H}$, et al. Correlations between lymph node metastasis and depth of submucosal invasion in submucosal invasive colorectal carcinoma: a Japanese collaborative study. J Gastroenterol 2004;39:534-43.

64. Japanese Society for Cancer of the Colon and Rectum. Japanese classification of colorectal, appendiceal, and anal carcinoma: the 3d English edition [secondary publication]. J Anus Rectum Colon 2019;3:175-95.

65. Kawachi H, Eishi Y, Ueno H, Nemoto T, Fujimori T, Iwashita A, et al. A three-tier classification system based on the depth of submucosal invasion and budding/sprouting can improve the treatment strategy for T1 colorectal cancer: a retrospective multicenter study. Mod Pathol 2015; 28:872-9.

66. Coton C, Lefevre JH, Debove C, Creavin B, Chafai N, Tiret E, et al. Does transanal local resection increase morbidity for subsequent total mesorectal excision for early rectal cancer? Colorectal Dis 2019;21:15-22.

67. Halverson AL, Morris AM, Cleary RK, Chang GJ. For patients with early rectal cancer, does local excision have an impact on recurrence, survival, and quality of life relative to radical resection? Ann Surg Oncol 2019;26:2497506.

68. Cutting JE, Hallam SE, Thomas MG, Messenger DE. A systematic review of local excision followed by adjuvant therapy in early rectal cancer: are PT1 tumours the limit? Colorectal Dis 2018;20:854-63.

69. Borstlap WA, Coeymans TJ, Tanis PJ, Marijnen CA, Cunningham C, Bemelman WA, et al. Meta-analysis of oncological outcomes after local excision of pT1-2 rectal cancer requiring adjuvant (chemo)radiotherapy or completion surgery. Br J Surg 2016;103:1105-16.

70. van Oostendorp SE, Smits L, Vroom Y, Detering R, Heymans MW, Moons L, et al. Local recurrence after local excision of early rectal cancer: a meta-analysis of completion TME, adjuvant (chemo) radiation, or no additional 
treatment. Br J Surg 2020;107:1719-30.

71. Chakravarti A, Compton CC, Shellito PC, Wood WC, Landry J, Machuta SR, et al. Long-term follow-up of patients with rectal cancer managed by local excision with and without adjuvant irradiation. Ann Surg 1999;230:4954.

72. Wentworth S, Russell GB, Tuner II, Levine EA, Mishra G, Waters GS, et al. Long-term results of local excision with and without chemoradiation for adenocarcinoma of the rectum. Clin Colorectal Cancer 2005;4:332-5.

73. Han SL, Zeng QQ, Shen X, Zheng XF, Guo SC, Yan JY. The indication and surgical results of local excision following radiotherapy for low rectal cancer. Colorectal Dis 2010; 12:1094-8.

74. Jeong JU, Nam TK, Kim HR, Shim HJ, Kim YH, Yoon MS, et al. Adjuvant chemoradiotherapy instead of revision radical resection after local excision for high-risk early rectal cancer. Radiat Oncol 2016;11:114.

75. Lee L, Kelly J, Nassif GJ, Atallah SB, Albert MR, Shridhar R, et al. Chemoradiation and local excision for T2N0 rectal cancer offers equivalent overall survival compared to standard resection: a national cancer database analysis. J Gastrointest Surg 2017;21:1666-74.

76. Borstlap WA, Tanis PJ, Koedam TW, Marijnen CA, Cunningham $C$, Dekker $E$, et al. A multi-centred randomised trial of radical surgery versus adjuvant chemoradiotherapy after local excision for early rectal cancer. BMC Cancer 2016;16:513.

77. Maas M, Beets-Tan RG, Lambregts DM, Lammering G, Nelemans PJ, Engelen SM, et al. Wait-and-see policy for clinical complete responders after chemoradiation for rectal cancer. J Clin Oncol 2011;29:4633-40.

78. Lee BC, Oh S, Lim SB, Yu CS, Kim JC. Transanal minimally-invasive surgery for treating patients with regressed rectal cancer after preoperative chemoradiotherapy. Ann Coloproctol 2017;33:52-6.

79. Park IJ, You YN, Agarwal A, Skibber JM, Rodriguez-Bigas MA, Eng C, et al. Neoadjuvant treatment response as an early response indicator for patients with rectal cancer. $J$ Clin Oncol 2012;30:1770-6.

80. Habr-Gama A, Sao Juliao GP, Vailati BB, Sabbaga J, Aguilar PB, Fernandez LM, et al. Organ preservation in CT2N0 rectal cancer after neoadjuvant chemoradiation therapy: the impact of radiation therapy dose-escalation and consolidation chemotherapy. Ann Surg 2019;269:102-7.

81. Hallam S, Messenger DE, Thomas MG. A systematic review of local excision after neoadjuvant therapy for rectal cancer: are ypT0 tumors the limit? Dis Colon Rectum 2016; 59:984-97.

82. Huh JW, Maeda K, Liu Z, Wang X, Roslani AC, Lee WY. Current status of "Watch-and-Wait" rectal cancer treatment in Asia-pacific countries. Ann Coloproctol 2020;36:70-7.

83. Rouleau-Fournier F, Brown CJ. Can less be more? Organ preservation strategies in the management of rectal cancer. Curr Oncol 2019;26(Suppl 1):S16-23.

84. Jeong SA, Park IJ, Hong SM, Bong JW, Choi HY, Seo JH, et al. Does total regression of primary rectal cancer after preoperative chemoradiotherapy represent "no tumor" status? Ann Surg Treat Res 2019;96:78-85.

85. Battersby NJ, How P, Moran B, Stelzner S, West NP, Branagan $\mathrm{G}$, et al. Prospective validation of a low rectal cancer magnetic resonance imaging staging system and development of a local recurrence risk stratification model: the MERCURY II study. Ann Surg 2016;263:751-60.

86. Lezoche E, Baldarelli M, Lezoche G, Paganini AM, Gesuita $\mathrm{R}$, Guerrieri M. Randomized clinical trial of endoluminal locoregional resection versus laparoscopic total mesorectal excision for T2 rectal cancer after neoadjuvant therapy. Br J Surg 2012;99:1211-8.

87. Garcia-Aguilar J, Renfro LA, Chow OS, Shi Q, Carrero XW, Lynn PB, et al. Organ preservation for clinical T2N0 distal rectal cancer using neoadjuvant chemoradiotherapy and local excision (ACOSOG Z6041): results of an open-label, single-arm, multi-institutional, phase 2 trial. Lancet Oncol 2015;16:1537-46.

88. Wawok P, Polkowski W, Richter P, Szczepkowski M, Oledzki J, Wierzbicki R, et al. Preoperative radiotherapy and local excision of rectal cancer: long-term results of a randomised study. Radiother Oncol 2018;127:396-403.

89. Bach SP, Gilbert A, Brock K, Korsgen S, Geh I, Hill J, et al. Radical surgery versus organ preservation via shortcourse radiotherapy followed by transanal endoscopic microsurgery for early-stage rectal cancer (TREC): a randomised, open-label feasibility study. Lancet Gastroenterol Hepatol 2021;6:92-105.

90. Garcia-Aguilar J, Shi Q, Thomas CR Jr, Chan E, Cataldo P, Marcet J, et al. A phase II trial of neoadjuvant chemoradiation and local excision for T2N0 rectal cancer: preliminary results of the ACOSOG Z6041 trial. Ann Surg Oncol 2012;19:384-91.

91. Rullier E, Rouanet P, Tuech JJ, Valverde A, Lelong B, Rivoire $M$, et al. Organ preservation for rectal cancer (GRECCAR 2): a prospective, randomised, open-label, multicentre, phase 3 trial. Lancet 2017;390:469-79. 
PRECISION AND FUTURE MEDICINE

Treatment strategy for early rectal cancer

92. Verseveld M, de Graaf EJ, Verhoef C, van Meerten E, Punt $\mathrm{CJ}$, de Hingh IH, et al. Chemoradiation therapy for rectal cancer in the distal rectum followed by organ-sparing tran- sanal endoscopic microsurgery (CARTS study). Br J Surg 2015;102:853-60. 